\title{
Análise histomorfométrica do útero na espécie canina do nascimento aos seis meses de idade
}

[Histomorphometric analysis of the uterus in dogs from birth to six months of age]

\author{
J.L.G. Ramos ${ }^{1}$, C.L.F.G. Ramos $^{2}$, I.C.N. Cunha ${ }^{2}$, E.C.Q. Carvalho ${ }^{2}$, \\ E. Shimoda ${ }^{3}$, M.R. $\mathrm{Luz}^{4}$
}

\author{
${ }^{1}$ Universidade Estadual do Norte Fluminense Darcy Ribeiro - UENF - Universidade Federal \\ Espírito Santo - UFES/CCA - Alegre, ES \\ ${ }^{2}$ Universidade Estadual do Norte Fluminense Darcy Ribeiro - UENF - Campos, RJ \\ ${ }^{3}$ Universidade Cândido Mendes, Instituto Cândido Mendes - UCAM - Campos, RJ \\ ${ }^{4}$ Escola de Veterinária - Universidade Federal de Minas Gerais - UFMG - Belo Horizonte, MG
}

\begin{abstract}
RESUMO
Objetivou-se caracterizar para a espécie canina o desenvolvimento histológico uterino do nascimento aos seis meses de idade. Foram analisados úteros $(n=32)$ de animais com idades entre um e 180 dias pósnascimento (DPN), distribuídos em oito grupos: G1-1 DPN (1 Yorkshire Terrier, 1 Poodle, 2 Sem Raça Definida (SRD)/peso médio $(\mathrm{Pm})=190 \mathrm{~g}), \mathrm{G} 2-15$ DPN (2 Yorkshire Terrier e 2 SRD/Pm=354g), G3-30 DPN (1 Rottweiler, 1 Poodle, 2 SRD/Pm=985g), G4-45 DPN (1 Poodle, 3 SRD/Pm=1,1kg), G5-60 DPN (1 Yorkshire Terrier, 1 Poodle e 2 SRD/Pm=1,4kg), G6-90 DPN (4 SRD/Pm=2,8kg), G7-120 DPN (1 Poodle e 3 SRD/Pm=6,6kg) e G8-180 DPN (1 Rottweiler, 1 Poodle e 2 SRD/Pm=11kg). A análise histológica constituiu de mensurações das espessuras $(\mu \mathrm{m})$ da parede uterina, miométrio, endométrio, assim como diâmetro $(\mu \mathrm{m})$ e número de glândulas endometriais. A análise estatística demonstrou estabilidade e homogeneidade nas estruturas avaliadas com coeficientes de variação baixos $(<10 \%)$. Observou-se: útero com um DPN: epitélio com células cúbicas simples, miométrio rudimentar, presença de perimétrio e ausência de glândulas endometriais; aos 15 DPN: desenvolvimento de estrutura primordial de formação das glândulas endometriais; dos 30 aos 45 DPN: endométrio e glândulas endometriais simples; aos 60 DPN: glândulas endometriais em lâmina própria com ramificações e discreto pregueamento endometrial; de 90 a 180 DPN: todas as estruturas uterinas apresentaram histoarquitetura de um animal maduro. Todas as variáveis analisadas apresentaram correlação positiva com a idade pós-nascimento $\left(\mathrm{R}^{2} \geq 72,2 \%\right)$. Conclui-se que o útero da cadela desenvolve-se continuamente do nascimento à 180 dias de vida e que apresenta-se desprovido de glândulas endometriais ao nascimento. As primeiras glândulas endometriais são observadas aos 15 dias de vida e apresenta conformação histológica de um animal adulto após 60 dias do nascimento.
\end{abstract}

Palavras-chave: canino, desenvolvimento uterino, glândulas endometriais, histologia

\begin{abstract}
This study aimed to characterize canine species' uterine histological development from birth to six months of age. Uteri $(n=32)$ of animals aged between one and 180 days postnatal $(P N D)$, distributed into eight groups were analyzed: G1-1 PND (1 Yorkshire Terrier, Poodle 1, 2 Mixed Breed (MB)/Medium weight $(M w)=190 g), G 2-15 P N D(2$ Yorkshire Terrier and $2 \mathrm{MB} / \mathrm{Mw}=354 \mathrm{~g}), \mathrm{G3}-30 \mathrm{PND}(1$ Rottweiler, 1 Poodle, $2 \mathrm{MB} / \mathrm{Mw}=985 \mathrm{~g}), \mathrm{G} 4-45 \mathrm{PND}$ (1 Poodle, $3 \mathrm{MB} / \mathrm{Mw}=1.1 \mathrm{~kg})$, G5-60 PND (1 Yorkshire Terrier, Poodle 1 and $2 \mathrm{MB} / \mathrm{Mw}=1.4 \mathrm{~kg}), \mathrm{G6}-90 \mathrm{PND}(4 \mathrm{MB} / \mathrm{Mw}=2.8 \mathrm{~kg}), \mathrm{G} 7-120 \mathrm{PND}$ (1 Poodle and $3 \mathrm{MB} / \mathrm{Mw}=6.6 \mathrm{~kg})$ and G8-180 PND (1 Rottweiler, Poodle 1 and $2 \mathrm{MB} / \mathrm{Mw}=11 \mathrm{~kg})$. Histological examination consisted of thickness measurement $(\mu \mathrm{m})$ of the uterine wall, myometrium, endometrium, as well as diameter $(\mu \mathrm{m})$ and number of endometrial glands. Statistical analysis showed
\end{abstract}

Recebido em 13 de fevereiro de 2014

Aceito em 21 de agosto de 2014

E-mail: jleonardoramos@hotmail.com 
stability and uniformity in the evaluated structures with low coefficients of variation $(<10 \%)$. We observed: uterus with one PND: simple cubic epithelium cells, rudimentary myometrium, perimetrium presence and absence of endometrial glands; at 15 PND: development of primordial structure formation of endometrial glands; from 30 to 45 PND: simple endometrium and endometrial glands; PND 60: endometrial glands in the lamina propria with branches and discreet endometrial pleating; 90-180 PND: uterine all structures presented histoarchitecture of a mature animal. All variables were positively correlated with postnatal age $(R 2 \geq 72.2 \%)$. It is concluded that the uterus of the bitch continuously evolves from birth to 180 days old and is presented devoid of endometrial glands at birth. The first endometrial glands are observed at 15 days of life and present histological conformation to an adult 60 days after birth.

Keywords: canine, uterine development, endometrial glands, histology

\section{INTRODUÇÃO}

O crescimento e desenvolvimento de um concepto dependem inicialmente do endométrio que primariamente fornece a nutrição pelas secreções produzidas pelas glândulas endometriais. As glândulas endometriais estão presentes no útero de todos os mamíferos e sua gênese envolve diferenciação e desenvolvimento do eptélio glandular (EG), do epitélio luminal (EL) e a penetração do estroma uterino por tubos e extenso enrolamento e ramificação do EG (Spencer e Bazer, 2004). Embora o papel funcional das glândulas endometriais tenha sido estabelecido na maioria dos mamíferos, mecanismos que regulam o desenvolvimento delas em animais domésticos, de laboratório e humanos ainda não são entendidos (Gray et al., 2001).

Eventos morfogenéticos comuns ao desenvolvimento de todo útero incluem: diferenciação e crescimento do miometrio; diferenciação e morfogenia das glândulas endometriais e organização e estratificação do estroma endometrial (Bartol et al., 1993; Bartol et al., 1999; Gray et al., 2000). O desenvolvimento uterino é iniciado no feto, mas só é completado com diferenciação e desenvolvimento das glândulas endometriais no período pós-nascimento (Spencer e Bazer, 2004). Os mecanismos que regulam a diferenciação uterina neonatal e a formação das glândulas endometriais são complexos e envolvem complexas interações entre o epitélio e mesênquima e são mediados pela composição e distribuição da matriz extracelular, presença de fatores de crescimento e expressão de receptores de hormônios esteroides (Stewart et al., 2011).
Os eventos cronológicos da morfogênese das glândulas endometriais são conhecidos em várias espécies, como: ovina, suína, humana e espécies de roedores (Gray et al., 2001). Entretanto, na espécie canina estes eventos não foram descritos, sendo apenas apresentados estudos histológicos e morfométricos em casos de processos patológicos como hiperplasia cística endometrial (HCE) e piometra (De Bosschere et al., 2001; Weiss et al., 2004; Oliveira et al., 2008), efeitos do uso de contraceptivos na histoarquitetura uterina (Sokolowski e Van Ravenswaay, 1976; Monteiro et al., 2009), comparação entre nulíparas e multíparas (Augsburger e Kurzi, 2004; Monteiro et al., 2009) e com distintos achados perante a análise histológica nas diversas fases do ciclo estral (Galabova et al., 2003).

Devido a ausência de estudos na espécie canina em relação à gênese das glândulas endometriais, este estudo teve como objetivo caracterizar o denvolvimento uterino em cadelas pré-puberes, desde o primeiro dia pós-nascimento até o sexto mês de idade.

\section{MATERIAL E MÉTODOS}

Após aprovado pelo comitê de ética local sob protocolo 2014-01234 o experimento foi conduzido nas dependências da Universidade Federal do Espírito Santo/Centro de Ciências Agrárias (UFES/CCA) e Universidade Estadual do Norte Fluminense Darcy Ribeiro (UENF), utilizando-se úteros $(n=32)$ da espécie canina provenientes de animais das seguintes raças: york Shire $(n=4)$, Poodles $(n=6)$, Rotweiller $(n=2)$ e Sem Raça Definida (SRD) $(n=20)$. As idades das cadelas variaram entre um e 180 dias de vida (dias pós-nascimento -DPN). 
Os animais foram distribuídos em oito grupos experimentais de acordo com a idade: G1 - 1 DPN (n=4); G2 - 15 DPN (n=4); G3 - 30 DPN $(\mathrm{n}=4) ; \mathrm{G} 4-45$ DPN $(\mathrm{n}=4) ; \mathrm{G} 5$ - 60 DPN $(\mathrm{n}=4)$; G6 - 90 DPN (n=4); G7 - 120 DPN (n=4) e G8 $180 \operatorname{DPN}(\mathrm{n}=4)$.

As coletas dos úteros foram realizadas em neonatos natimortos (G1), filhotes que vieram a óbito no decorrer de seu desenvolvimento, sem afecções uterinas (G2 a G7) ou após ovariosalpingohisterectomia (OSH) (G8).

Para a OSH as cadelas foram submetidas a jejum sólido de 12 horas e hídrico de 6 horas. Previamente ao procedimento cirúrgico, as cadelas foram submetidas a fluidoterapia intravenosa com solução de $\mathrm{NaCl}$ 0,9\%. Em seguida, foi administrado sulfato de atropina $(0,044 \mathrm{mg} / \mathrm{kg} / \mathrm{SC})$ e 15 minutos após, cloridrato de xilazina $2 \% \quad(1,5 \mathrm{mg} / \mathrm{kg} / \mathrm{IM})$. A indução anestésica foi feita com tiopental sódico 2,5\% $(12,5 \mathrm{mg} / \mathrm{kg} / \mathrm{IV})$. Após a intubação orotraqueal, a anestesia foi mantida com isoflurano em circuito com reinalação parcial de gases.

A analgesia pós-operatória foi realizada com flunixin meglumine $(1,0 \mathrm{mg} / \mathrm{kg} / \mathrm{IM})$ durante três dias. O antibiótico utilizado no pós-operatório foi enrofloxacina na dose de $5 \mathrm{mg} / \mathrm{kg}$, por via IM, a cada $12 \mathrm{~h}$, durante sete dias.

Para avaliação histológica, fragmentos de $0,5 \mathrm{~cm}$ do terço médio dos cornos uterinos foram colhidos e fixados em paraformaldeído tamponado a $10 \%$. Posteriormente, foram processados e incluídos em parafina (Junqueira,

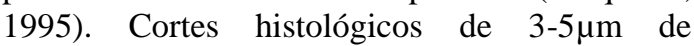
espessura foram submetidos à desparafinização seguindo protocolo padrão, foram corados com Hematoxilina-Eosina (HE) e examinados ao microscópio de luz com magnitude de 10 a 100x.

Foram analisados o tipo de epitélio superficial, presença e quantidade de glândulas endometriais e as disposições das fibras do tecido conjuntivo do endométrio e das fibras do estrato muscular. As mensurações efetuadas foram: espessura da parede uterina $(\mu \mathrm{m})$, espessura do endométrio $(\mu \mathrm{m})$ e miométrio $(\mu \mathrm{m})$, em cinco campos diferentes de cada amostra histológica; diâmetro $(\mu \mathrm{m})$ das glândulas endometriais, sendo analisadas 10 glândulas em cada amostra histológica, e o número de glândulas endometriais $/ \mathrm{mm}^{2}$, utilizando-se magnitude de 10x.

As mensurações foram realizadas utilizando-se o programa Imaje J 1.43u (Wayne Rasband, National Institutes of Health, USA).

Os resultados das avaliações histológicas foram apresentados de forma descritiva. Os dados foram analisados utilizando análise de regressão com uso do Sistema para Análises Estatísticas (SAEG), versão 9.1 (Sistema..., 2007). As variáveis analisadas foram espessura da parede uterina $(\mu \mathrm{m})$, espessura do miométrio $(\mu \mathrm{m}) \mathrm{e}$ endométrio $(\mu \mathrm{m})$, diâmetro $(\mu \mathrm{m})$ das glândulas endometriais e $o$ número de glândulas endometriais $/ \mathrm{mm}^{2}$, observando a interação destas com a idade pós-nascimento. Foram demonstradas médias, erro padrão e coeficiente de variação. Foi considerado o nível de significância de $5 \%$.

\section{RESULTADOS}

A análise histológica do útero dos animais do G1 ao G8 revelou (Fig.1):

Fêmeas com 1 dia de idade (G1): Endométrio com presença de epitélio colunar com células cúbicas simples apoiadas sobre estroma mesenquimal em organização. Miométrio rudimentar envolvendo a lâmina própria (lúmen endometrial), e ausência de glândulas endometriais. Perimétrio presente constituído de tecido conjuntivo e revestido por mesotélio.

Fêmeas com 15 dias de idade (G2): Endométrio com epitélio cúbico simples, presença de glândulas endometriais tubulares rudimentares e presença de pequenas invaginações no lúmen endometrial. Miométrio rudimentar, pouco definido, com presença de pequenos vasos sanguíneos. Perimétrio constituído de tecido conjuntivo.

Fêmeas com 30 a 45 dias de idade (G3 e G4): Endométrio com epitélio cúbico simples, com lâmina própria e presença de glândulas endometriais simples, com poucas ramificações. Miométrio constituído por músculo liso e estrato vascular presente com discreta presença de vasos. Perimétrio constituído de tecido conjuntivo frouxo. 
Fêmeas com 60 dias de idade (G5): Endométrio com epitélio cúbico simples, discreto pregueamento, lâmina própria com presença de glândulas endometriais tubulares ramificadas. Miométrio constituído por camadas de músculo liso (miométrio interno e externo), extrato vascular com vasos sanguíneos de diferentes calibres. Perimétrio presente e constituído de tecido conjuntivo frouxo.

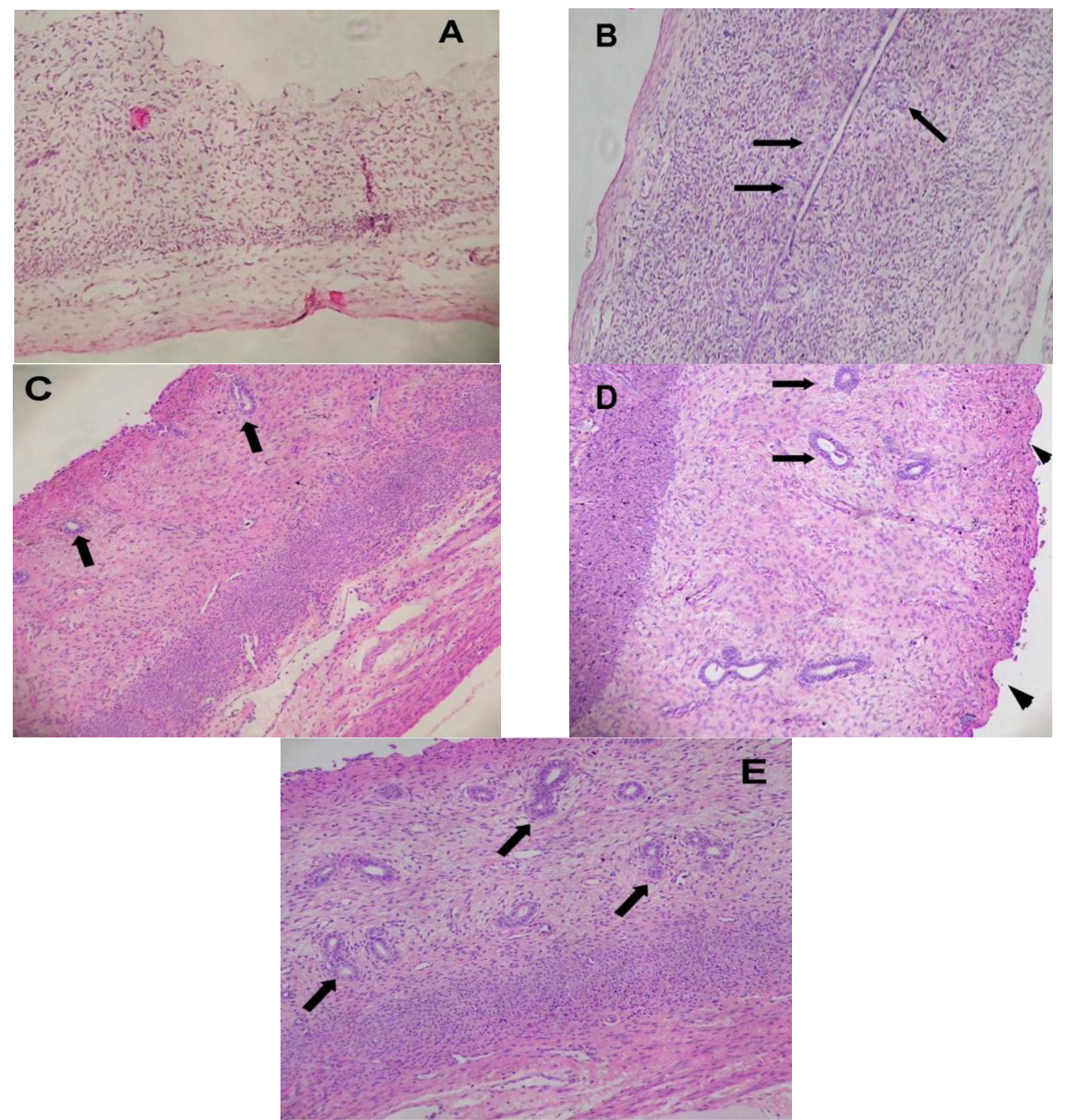

Fêmeas com 90, 120 e 180 dias de idade (G6, G7 e G8): Estrutura histológica similar aos animais do G4 e G5, endométrio com epitélio cúbico simples, discreto pregueamento, lâmina própria com presença de gândulas endometrias, diferindo apenas na presença de maior quantidade destas. Miométrio constituído por camadas de músculo liso e extrato vascular com vasos sanguineos de diferentes calibres. Perimétrio presente e constituído de tecido conjuntivo frouxo.

Figura 1. Fotomicrografias do útero da espécie canina do nascimento aos seis meses de idade. A)1 DPN Útero com ausência de glândulas endometriais; B) 15 DPN - Presença de glândulas endometriais rudimentares (setas); C) 30 DPN e 45 DPN - Glândulas endometriais simples, poucas ramificações (setas); D) 60 DPN - Glândulas endometriais simples (setas) e início de pregueamento do endométrio (cabeças de seta); E) 120 DPN e 180 DPN - Aumento do número de glândulas presentes em lâmina própria (setas) ( $\mathrm{HE}$, magnitude 10x). 
Os animais do G1 apresentaram estrutura uterina simples, o que possibilitou apenas mensurar a parede uterina total, a qual apresentou $239,67 \pm 2,73 \mu \mathrm{m}$ e ausência de estruturas glandulares em lâmina própria. A mensuração de endométrio e miométrio separadamente não foi possível devido a característica rudimentar destes tecidos em formação.

Nos animais do G2, G3 e G4 foi possível mensurar estruturas uterinas diferenciadas como parede uterina total, endométrio, miométrio, número e diâmetro das glândulas, cujos resultados estão apresentados na Tab. 1.
Nos animais do G5, G6, G7 e G8 foi possível avaliar todas as estruturas anteriormente citadas, além da possibilidade de se avaliar a altura do epitélio, e o desenvolvimento das estruturas com o aumento da idade. Além disso, foi observada estabilidade e homogeneidade das estruturas avaliadas (Tab.1). Observou-se correlação significativa $(\mathrm{P}<0,0001)$ entre todas as variáveis analisadas com a idade animal, parede uterina $\left(\mathrm{R}^{2}=97,4 \%\right)$, endométrio $\left(\mathrm{R}^{2}=99,4 \%\right)$, miométrio $\left(\mathrm{R}^{2}=95,8 \%\right)$, numero de glândulas endometriais $\left(\mathrm{R}^{2}=92,3 \%\right)$ diâmetro das glândulas endometriais $\left(\mathrm{R}^{2}=94,1 \%\right)$ e altura do epitélio $\left(\mathrm{R}^{2}=72,2 \%\right)($ Tab.2).

Tabela 1. Dados histomorfométricos do útero de cães pré-púberes com idades entre 1 e 180 dias pósnascimento (médias $\pm \mathrm{EP} ; \mathrm{CV}$ )

\begin{tabular}{|c|c|c|c|c|c|c|}
\hline Grupos Variável & $\begin{array}{l}\text { EPU } \\
(\mu \mathrm{m})\end{array}$ & $\begin{array}{c}\mathrm{EM} \\
(\mu \mathrm{m})\end{array}$ & $\begin{array}{c}\mathrm{EE} \\
(\mu \mathrm{m})\end{array}$ & $\begin{array}{l}\mathrm{N}^{\circ} \mathrm{Gl} \\
\left(\mathrm{mm}^{2}\right)\end{array}$ & $\begin{array}{l}\text { DGl } \\
(\mu \mathrm{m})\end{array}$ & $\begin{array}{c}\mathrm{AE} \\
(\mu \mathrm{m})\end{array}$ \\
\hline G1: 1DPN & $\begin{array}{c}239,67 \pm 2,73 \\
(C V=1,14)\end{array}$ & --- & --- & --- & --- & --- \\
\hline G2: 15 DPN & $\begin{array}{c}281,47 \pm 2,12 \\
(\mathrm{CV}=0,75)\end{array}$ & $\begin{array}{c}231,38 \pm 1,94 \\
(\mathrm{CV}=0,84)\end{array}$ & $\begin{array}{l}51,98 \pm 1,09 \\
(\mathrm{CV}=2,10)\end{array}$ & $\begin{array}{l}1,60 \pm 0,15 \\
(\mathrm{CV}=9,51)\end{array}$ & $\begin{array}{l}10,10 \pm 0,17 \\
(\mathrm{CV}=1,71)\end{array}$ & --- \\
\hline G3: $30 \mathrm{DPN}$ & $\begin{array}{c}319,98 \pm 2,21 \\
(\mathrm{CV}=0,69)\end{array}$ & $\begin{array}{c}260,47 \pm 1,68 \\
(C V=0,65)\end{array}$ & $\begin{array}{l}61,33 \pm 1,02 \\
(\mathrm{CV}=1,66)\end{array}$ & $\begin{array}{l}3,90 \pm 0,16 \\
(\mathrm{CV}=4,12)\end{array}$ & $\begin{array}{l}11,82 \pm 0,16 \\
(\mathrm{CV}=1,36)\end{array}$ & --- \\
\hline G4: 45 DPN & $\begin{array}{c}451,66 \pm 3,99 \\
(\mathrm{CV}=0,88)\end{array}$ & $\begin{array}{c}366,47 \pm 3,31 \\
(\mathrm{CV}=0,90)\end{array}$ & $\begin{array}{l}87,21 \pm 1,34 \\
(\mathrm{CV}=1,53)\end{array}$ & $\begin{array}{l}3,85 \pm 0,20 \\
(\mathrm{CV}=5,08)\end{array}$ & $\begin{array}{l}18,76 \pm 0,19 \\
(\mathrm{CV}=0,99)\end{array}$ & --- \\
\hline G5: $60 \mathrm{DPN}$ & $\begin{array}{c}496,77 \pm 1,44 \\
(\mathrm{CV}=0,29)\end{array}$ & $\begin{array}{c}399,31 \pm 0,96 \\
(C V=0,24)\end{array}$ & $\begin{array}{l}99,51 \pm 1,04 \\
(\mathrm{CV}=1,05)\end{array}$ & $\begin{array}{l}6,00 \pm 0,19 \\
(\mathrm{CV}=3,20)\end{array}$ & $\begin{array}{c}21,37 \pm 0,13 \\
(\mathrm{CV}=0,59\end{array}$ & $\begin{array}{l}4,66 \pm 0,08 \\
(\mathrm{CV}=1,68)\end{array}$ \\
\hline G6: 90 DPN & $\begin{array}{c}669,88 \pm 6,14 \\
(\mathrm{CV}=0,92)\end{array}$ & $\begin{array}{c}540,68 \pm 5,10 \\
(\mathrm{CV}=0,94)\end{array}$ & $\begin{array}{c}132,11 \pm 1,24 \\
(\mathrm{CV}=0,94)\end{array}$ & $\begin{array}{l}7,80 \pm 0,22 \\
(\mathrm{CV}=2,88)\end{array}$ & $\begin{array}{l}22,37 \pm 0,10 \\
(\mathrm{CV}=0,43)\end{array}$ & $\begin{array}{l}4,87 \pm 0,08 \\
(\mathrm{CV}=1,65)\end{array}$ \\
\hline G7: 120DPN & $\begin{array}{c}875,06 \pm 8,66 \\
(C V=0,99)\end{array}$ & $\begin{array}{c}705,62 \pm 7,40 \\
(C V=1,05)\end{array}$ & $\begin{array}{c}179,27 \pm 5,53 \\
(\mathrm{CV}=3,08)\end{array}$ & $\begin{array}{l}10,35 \pm 0,24 \\
(\mathrm{CV}=2,35)\end{array}$ & $\begin{array}{l}23,59 \pm 0,09 \\
(\mathrm{CV}=0,37)\end{array}$ & $\begin{array}{l}5,09 \pm 0,03 \\
(\mathrm{CV}=0,62)\end{array}$ \\
\hline G8: 180DPN & $\begin{array}{c}978,61 \pm 9,70 \\
(C V=0,99)\end{array}$ & $\begin{array}{c}693,77 \pm 6,99 \\
(\mathrm{CV}=1,01)\end{array}$ & $\begin{array}{c}301,68 \pm 2,16 \\
(\mathrm{CV}=0,71)\end{array}$ & $\begin{array}{l}11,50 \pm 0,59 \\
(\mathrm{CV}=5,11)\end{array}$ & $\begin{array}{l}24,37 \pm 0,14 \\
(\mathrm{CV}=0,59)\end{array}$ & $\begin{array}{l}5,55 \pm 0,07 \\
(\mathrm{CV}=1,27)\end{array}$ \\
\hline
\end{tabular}

$\overline{\mathrm{EPU}}=$ Espessura de parede uterina; $\mathrm{EM}=$ Espessura de miométrio; $\mathrm{EE}=$ Espessura de endométrio; $\mathrm{N}^{\circ} \mathrm{Gl}=$ Número de glândulas endometriais; D Gl = Diâmetro das glândulas endometriais; AE = Altura do Epitélio; DPN = Dias pósnascimento; $\mathrm{CV}$ = Coeficiente de Variação \%; $\mathrm{EP}$ = erro padrão; --- = não avaliado. 
Tabela 2. Equações de regressão das avaliações histomorfométricas do útero de cães pré-púberes com idades entre um e 180 dias pós-nascimento, com respectivos coeficientes de determinação $\left(R^{2}\right)$ e significância $(\mathrm{P})$

\begin{tabular}{clcc}
$\begin{array}{c}\text { Variáv } \\
\text { el }\end{array}$ & \multicolumn{1}{c}{ Equação de Regressão } & $\begin{array}{c}\text { Coeficiente } \\
\left(\mathrm{R}^{2}\right)\end{array}$ & Significância \\
\hline EPU & $\hat{\mathrm{Y}}=189,269+6,29236 . \mathrm{X}-0,00981712 . \mathrm{X}^{2}$ & $(97,4 \%)$ & $\mathrm{P}<0,0001$ \\
$\mathrm{EM}$ & $\hat{\mathrm{Y}}=95,1666+6,87754 . \mathrm{X}-0,0191789 . \mathrm{X}^{2}$ & $(95,8 \%)$ & $\mathrm{P}<0,0001$ \\
$\mathrm{EE}$ & $\hat{\mathrm{Y}}=43,4684+0,606810 . \mathrm{X}+0,00455978 . \mathrm{X}^{2}$ & $(99,4 \%)$ & $\mathrm{P}<0,0001$ \\
$\mathrm{~N}^{\circ} \mathrm{Gl}$ & $\hat{\mathrm{Y}}=-0,0179917+0,116197 . \mathrm{X}-0,000285817 . \mathrm{X}^{2}$ & $(92,3 \%)$ & $\mathrm{P}<0,0001$ \\
$\mathrm{DGl}$ & $\hat{\mathrm{Y}}=-0,0801541+5,27062 . \mathrm{X}-0,213790 . \mathrm{X}^{2}$ & $(94,1 \%)$ & $\mathrm{P}<0,0001$ \\
$\mathrm{AE}$ & $\hat{\mathrm{Y}}=4,2600+0,00639167 . \mathrm{X}-0,00000416667 . \mathrm{X}^{2}$ & $(72,2 \%)$ & $\mathrm{P}<0,0001$ \\
\hline
\end{tabular}

EPU = Espessura da parede uterina $(\mu \mathrm{m}) ; \mathrm{EM}=$ Espessura do miométrio $(\mu \mathrm{m}) ; \mathrm{EE}=$ Espessura do endométrio $(\mu \mathrm{m})$; $\mathrm{N}^{\circ} \mathrm{Gl}=$ Número de glândulas endometriais; $\mathrm{DGl}=$ Diâmetro das glândulas endometriais $(\mu \mathrm{m}) ; \mathrm{AE}=$ Altura do Epitélio $(\mu \mathrm{m})$.

\section{DISCUSSÃO}

No presente estudo, as fêmeas com um dia pósnascimento apresentaram útero com epitélio colunar cúbico simples e ausência de glândulas endometriais, as quais começaram a ser identificadas, mesmo que em suas estruturas ainda rudimentares, a partir do décimo quinto dia pós-nascimento e apresentando sua histoarquitetura típica de uma fêmea madura após o sexagésimo dia pós-nascimento. Estes achados estão de acordo com o descrito por Gray et al. (2001) e Yin e Ma (2005) que descreveram a adenogênese uterina como um evento pósnascimento na maioria dos mamíferos, com evolução altamente espécie especifica e caracterizada pela diferenciação do epitélio glandular a partir do epitélio luminal (Bartol et al., 1993, 1999; Gray et al., 2000). Em roedores a invaginação epitelial é primeiramente observada com cinco DPN, porém em bovinos, ovinos e suínos observa-se já no dia pós-nascimento. Todavia, o desenvolvimento uterino em alguns animais (humanos, outros primatas e eqüinos) é iniciado no feto (vida intrauterina), mas só é completado com diferenciação e desenvolvimento das glândulas endometriais no período pós natal (Spencer e Bazer, 2004; Yin e Ma, 2005). Não é descrito na literatura o porquê da diferença entre as espécies do desenvolvimento uterino e principalmente das glândulas endometriais pré ou pós-nascimento, porém, a chave deste desenvolvimento pode estar na similaridade do desenvolvimento entre os animais das espécies prolíferas (ratas, suínos e cães) e espécies menos prolíferas (humanos, outros primata e equinos).

As primeiras glândulas endometriais foram observadas aos 15 DPN, porém apresentaram-se morfologicamente desenvolvidas apenas aos 60 dias pós-nascimento. Comparativamente, porcas tambêm nascem com ausência de glândulas em seu endométrio, mas por volta de 56 DPN a população de glândulas é densa e extensa (Spencer et al., 1993; Christenson et al., 1997; Tarleton et al., 1998; Yin e Ma, 2005, Monteiro e carvalho, 2006). Em ovelhas, o desenvolvimento glandular é iniciado entre o nascimento e sete DPN com a histoarquitetura semelhante a do útero adulto por volta de 56 DPN (Taylor et al., 2000; Yin e Ma, 2005). No útero de ratas a adenogênese inicia-se entre os dias cinco e nove pós-nascimento e completa-se por volta do dia 15 DPN (Branham et al., 1985; Yin e Ma, 2005). Como nos suínos, ovinos e ratas a cadela apresenta desenvolvimento glandular endometrial pósnascimento, apresentando como característica reprodutiva similar entre essas espécies a serem prolíferas e apresentar rápido início da maturidade sexual.

Como esperado, no presente estudo a espessura da parede uterina total variou crescentemente entre um e 180 DPN $(239,67 \pm 2,73$ a $978,61 \pm 9,70 \mu \mathrm{m})$. A espessura total média aos $180 \mathrm{DPN}$ foi inferior a observada por Monteiro 
et al. (2009) em cadelas nulíparas, com idade variando entre três meses e dois anos, que obtiveram 1272,9 $\pm 159,4 \mu \mathrm{m}$. As mensurações de endométrio também foram inferiores em comparação a estes autores $(301,68 \pm 2,16$ versus $611,0 \pm 55,9 \mu \mathrm{m})$. Estas diferenças podem ser explicadas pelo fato de os animais do presente experimento serem pré-púberes, ou seja, ainda não tinham sofrido as intensas atividades ocasionadas pelos esteróides sexuais durante o ciclo estral.

O miométrio das cadelas estudadas apresentou-se indiferenciado nos animais com um dia pósnascimento, rudimentar e com pequenos vasos sanguíneos aos 15 DPN, e com formação completa entre o $30^{\circ}$ e $45^{\circ}$ dias pós-nascimento, com aumento de sua espessura ao decorrer do tempo. Estes resultados estão de acordo com Ceroula et al. (1983) que relataram aumento da espessura do miométrio em suínos após 45 DPN.

Com relação ao perimétrio das cadelas estudadas, o mesmo esteve presente em todos os grupos estudados, desde um até 180 DPN. Todavia, inicialmente era constituído por uma camada espessa de tecido conjuntivo frouxo revestido por mesotélio, e apresentando características típicas de um animal adulto a partir de 60 DPN. Similarmente, Carvalho e Monteiro (2006) relataram que em suínos prépuberes o perimétrio também era típico e constituído de tecido conjuntivo frouxo sendo o mesmo descrito por Augsburger e Kurzi (2004) em cadelas da raça Beagle nulíparas e multíparas.

No presente estudo evidenciou-se que o útero da cadela apresenta desenvolvimento contínuo, desde o nascimento até o período de $180 \mathrm{DPN}$, com melhor caracterização e evidenciação de suas estruturas, principalmente das glândulas endometriais, a partir de 60 DPN. Entretanto, em estudos realizados por Erices e Schnurrbusch (1979), foi observado que na espécie suína o desenvolvimento uterino não é contínuo, havendo maior crescimento do endométrio e miométrio aos três meses de idade, com pouca variação no número de glândulas e do endométrio após este período, e revelando estabilidade do crescimento aos 180 dias pós-nascimento. De acordo com Bartol et al.
(1993), as transformações morfológicas do desenvolvimento uterino em suínos ocorrem do período pós-nascimento até o quarto mês de vida, com aparecimento e desenvolvimento de glândulas endometriais, aparecimento de dobras no endométrio e desenvolvimento do miométrio. Monteiro e Carvalho (2006) trabalhando com suínos concluíram que existem diferenças evidentes na evolução entre os órgãos das fêmeas recém-nascidas e pré-púberes, não ocorrendo o mesmo entre as porcas pré-púberes e púberes. $\mathrm{O}$ que observamos na cadela é um desenvolvimento contínuo do útero desde o nascimento até os 180 DPN e apresenta intensas modificações sobre ação dos hormônios gonadais (estrógeno e progesterona), principalmente pós-puberdade ocasionando intensas modificações nas estruturas uterinas e principalmente das glândulas endometriais.

Com a realização das análises de regressão, pôde-se observar correlação positiva e significativa $(\mathrm{P}<0,0001)$ entre todas as variáveis (espessura total da parede uterina, espessura total do miométrio, endométrio total do endométrio, diâmetro das glândulas endometriais e número de glândulas endometriais $/ \mathrm{mm}^{2}$ ) com a idade do animal, e por meio das equações de regressão quadráticas, foi demonstrado que a partir de determinado momento as estruturas avaliadas não mais se alteram, ou seja, atingem estabilidade, desde que isentas de influências biológicas, como alterações hormonais, afecções, ou da própria idade do animal.

\section{CONCLUSÕES}

Conclui-se que o útero da cadela desenvolve-se continuamente entre o nascimento e 180 dias de vida e que o mesmo apresenta-se desprovido de glândulas endometriais ao nascimento. As primeiras glândulas endometriais são observadas aos 15 dias pós-nascimento e o útero canino apresenta conformação morfológica de um animal adulto após 60 dias do nascimento.

\section{AGRADECIMENTOS}

A Fundação de Apoio a Ciência e Tecnologia do Espírito Santo - FAPES, pela concessão da bolsa de estudo. 


\section{REFERÊNCIAS}

AUGSBURGER R.H.; KURZI M. Histomorphologic and morphometric evaluation of the uterine horns in nulliparous and multiparous beagles. Am. J. Vet. Res., v.65, p.552-558, 2004.

BARTOL, F.F.; WILEY, A.A.; SPENCER, T.E. et al. Early uterine development in pigs. J. Reprod. Fertil. Suppl., v.48, p.99-116, 1993.

BARTOL, F.F.; WILEY, A.A.; FLOYD, J.G. et al. Uterine differentiation as a foundation for subsequent fertility. J. Reprod. Fertil. Suppl., v.54, p.287-302, 1999.

BRANHAM, W.S.; SHEEHAN, D.M. Ovarian and adrenal contributions to postnatal growth and differentiation of the rat uterus. Biol. Reprod., v.53, p.863-872, 1995

CHRISTENSON, R.K.; BARTOL, F.F.; VALLET, J.L. et al. Comparative study of uterine morphogenesis and protein secretion in neonatal White crossbred and Meishan gilts. Biol. Reprod., v.56, p.1112-1129, 1997.

DE BOSSCHERE, H.; DUCATELLE, R.; VERMEIRSCH, H. et al. Cystic endometrial hyperplasia - piometra complex in the bitch: Should the two entities be disconnected? Theriogenology, v.55, p.1509-1519, 2001.

ERICES, J.; SCHNURRBUSCH, U. Uterus development in swine from birth to 8 months of age. Arch. Experimen. Vet., v.33, p.457-473, 1979.

GALABOVA, G.; EGERBACHER, M.; AURICH, J.E. et al. Morphological changes of the endometrial epithelium in the bitch during metoestrus and anoestrus. Reprod. Domest. Anim., v.38, p.415-420, 2003.

GRAY, C.A.; JOHNSON, G.A.; BARTOL, F.F. et al. Developmental biology of uterine glands. Biol. Reprod., v.65, p.1311-1323, 2001.

GRAY, C.A.; BARTOL, F.F.; TAYLOR, K.M. et al. Ovine uterine gland knock-out model: Effects of gland ablation on the estrous cycle. Biol. Reprod., v.62, p.448-456, 2000.

JUNQUEIRA, L.C.U. Histology revisited - Technical improvement promoted by the use of hydrophilic resin embedding. Cienc. Cult., v.47, p.92-95, 1995.
MONTEIRO, C.M.R.; CARVALHO, R.C. Caracterização histológica do útero, tubas uterinas e ovários de fêmeas recém-nascidas, pré-púberes e púberes de suínos mestiços (Sus scrofa domestica - L. 1758) ARS Vet., v.22, p.223-228, 2006.

MONTEIRO, C.M.R.; PERRI, S.H.V.; CARVALHO, R.C.; KOIVISTO, M.B. Histologia e morfometria em cornos uterinos de cadelas nulíparas, multíparas e tratadas com contraceptivos. Pesq. Vet. Bras., v.29, p.847-851, 2009.

SISTEMA para Análises Estatísticas (SAEG), versão 9.1 (2007)

SOKOLOWSKI J.H.; VANRAVENSWAAY, F. Effects of melengestrol acetate on reproduction in the Beagle bitch. Am. J. Vet. Res., v.8, p.943-945, 1976.

SPENCER, T.; BAZER, F.W. Uterine and placental factors regulating conceptus growth in domestic animals. J. Anim. Sci., v.82, p.E4-E13, 2004

SPENCER, T.E.; BARTOL, F.F.; WILEY, A.A. et al. Neonatal porcine endometrial development involves coordinated changes in DNA synthesis, glycosaminoglycan distribution, and $3 \mathrm{H}$-glucosamine labeling. Biol. Reprod., v.46, p.729-740, 1993.

STEWART, C.A.; FISHER, S.J.; WANG, Y. et al. Uterine gland formation in mice is a continuous process, requiring the ovary after puberty, but not after parturition. Biol. Reprod., v.85, p.954-964, 2011.

TARLETON, B.J.; WILEY, A.A.; SPENCER, T.E. et $a l$. Ovary-independent estrogen receptor expression in neonatal porcine endometrium. Biol. Reprod., v.58, p.1009-1019, 1998.

TAYLOR, K.M.; GRAY, C.A.; JOYCE, M.M. et al. Neonatal ovine uterine development involves alterations in expression of receptors for estrogen, progesterone, and prolactin. Biol. Reprod., v.63, p.1192-1204, 2000

WEISS, R.R.; CALOMENO, M.A.; SOUSA, R.S. et al. Avaliação histopatológica, hormonal e bacteriológica da piometra na cadela. Arch. Vet. Sci., v.9, p.81-87, 2004.

YIN, Y.; MA, L. Development of the mammalian female reproductive tract. J. Biochem., v.137, p.677683,2005 